\title{
Comparison of Efficacy of Prophylactic versus Therapeutic Phototherapy in Preterm Neonates
}

\author{
Fouzia Ishaq ${ }^{1}$, Sidra Sehrish², Asma Anwar ${ }^{3}$, Rameeza Kaleem ${ }^{4}$, Summaira Naveed ${ }^{5}$, Tayyba Rahat ${ }^{6}$
}

1,3,4Department of Pediatrics, Fatima Jinnah Medical University / Sir Ganga Ram Hospital, Lahore-Pakistan, 2Department of Pediatrics, Allied Hospital, Faisalabad-Pakistan, ${ }^{5 D e p a r t m e n t}$
of Pediatrics, Services Institute of Medical Sciences, Lahore-Pakistan, ${ }^{6}$ Department of Statics, Pakistan Research Health Council, Lahore-Pakistan

\section{ABSTRACT}

Background: Jaundice neonatorum may predisposes preterm to develop bilirubin induced neurologic dysfunction even at lower total serum bilirubin level than term infant. Prophylactic phototherapy helps to maintain a lower serum bilirubin level may reduce the need for exchange transfusion in order to prevent kernicterus. Objective: To compare the efficacy of prophylactic versus therapeutic phototherapy among preterm neonates in reducing the frequency of exchange transfusion. Study Design: Randomized Controlled Trial. Settings: Neonatal Unit of Pediatrics department, Sir Ganga Ram Hospital Lahore-Pakistan. Duration: September 2018 to June 2019. Methodology: Two hundred preterm admitted in neonatal unit were enrolled and divided into 2 groups (A and B) using random numbers. Prophylactic phototherapy was initiated in Group A neonates within first 6 hours of life while it was applied when the serum bilirubin has reached to a pre-specified level in Group B. Daily total serum bilirubin level (also direct and indirect) was measured. Efficacy was measured in terms of preventing exchange transfusion. Data was entered and analyzed with SPSS version 21. Chi square was applied to compare efficacy between two groups with $p<0.05$ as significant. Results: Mean gestational age was $35.4 \pm 0.9$ weeks in group A and $35.6 \pm 0.7$ weeks in group B. There were $54 \%$ males and $46 \%$ females in group A while $51 \%$ males and $49 \%$ females in group B. The peak mean serum bilirubin level was observed on $3^{\text {rd }}$ and $4^{\text {th }}$ days in groups $A$ and $B$ respectively. Jaundiced neonates who received exchange transfusion in group $A$ and $B$ were $3 \%$ and $8 \%$ respectively $(p=0.1209)$. Prophylactic phototherapy found efficacious in $97 \%$ preterm although, they received it for longer duration (147 \pm 34.25 vs $98 \pm 27.10$ hours) ( $p$ 0.00001). Conclusion: Neonates received prophylactic phototherapy required less exchange transfusions compared to therapeutic group.

Keywords: Preterm, Phototherapy, Neonatal jaundice.

Corresponding Author

Submitted for Publication: 13-09-2019

Accepted for Publication: 16-06-2020

Dr. Fouzia Ishaq, Associate Professor, Department of Pediatrics, Fatima Jinnah Medical University / Sir Ganga Ram Hospital, Lahore-Pakistan. Email: fouziahasnain@hotmail.com

Citation: Ishaq F, Sehrish S, Anwar A, Kaleem R, Naveed S, Rahat T. Comparison of Efficacy of Prophylactic Versus Therapeutic Phototherapy in Preterm Neonates. APMC 2020;14(3):249-53.

DOI: $10.29054 / A P M C / 2020.683$

\section{INTRODUCTION}

Neonatal jaundice is a common occurrence in the newborn nursery manifested as yellow discoloration of the sclera and skin of neonates caused by hyperbilirubinemia. It is seen in $80 \%$ of preterm and $60 \%$ of term babies. ${ }^{1}$ During the first month of life, it contributes to $35 \%$ hospital admissions. ${ }^{2,3}$ Worldwide, severe neonatal jaundice (SNJ) is reported to affect 4,81000 neonates annually, of whom 63000 survive with neurocognitive impairment. ${ }^{4}$ Low and Middle Income Countries are found to have high burden of SNJ that need to be addressed to prevent disabilities in infants. 2,5

Bilirubin is a normal product derived from mainly hemoglobin catabolism. Its mild elevation in newborn is benign, needs no intervention. However, $10 \%$ of these may acquire severe jaundice necessitating intervention to halt brain dysfunction. Several factors related to unconjugated hyperbilirubinemia include large red cell mass, hepatic immaturity with decrease bilirubin conjugation and red blood cell destruction. Moreover, preterm and low birth weight are additional risk factors that exaggerate this phenomenon and predisposed the neonates to develop jaundice. ${ }^{6}$

Approximately more than $50 \%$ preterm have clinically significant levels that warrant treatment. ${ }^{7}$ Preterm infants may be at risk with the serum bilirubin concentration of $15 \mathrm{mg} / \mathrm{dl}$ or less because of their low serum albumin levels, however they are also frequently hypoxic, acidotic or otherwise distressed, placing them at risk for kernicterus at even lower bilirubin level than mature infants. Phototherapy, IVIG and exchange transfusion (ET) are well recognized modes of treatment resulted as significant decline in rate of neonatal jaundice., 8,9 lf left untreated, elevated unconjugated bilirubin can cause permanent brain impairment or death. ${ }^{10}$

The exchange transfusion (ET) has a pivotal role in the management of neonatal hyperbilirubinemia but the associated complications make it difficult to perform in NNU which are ill equipped to handle such events. Although, access to ET is often inadequate among underprivileged population ${ }^{11}$ but studies from LMICs reported high prevalence $(22 \%-86 \%)$ of ET particularly Nigeria, ${ }^{12,13}$ India ${ }^{14}$ and Bolivia. ${ }^{15}$ It is imperative to offer effective phototherapy before actually ET is required. Phototherapy is a simple, cheap and easily available way to manage neonatal jaundice with minimal side effects. Prophylactic phototherapy benefits to switch a lesser serum bilirubin levels which may reduce the need for exchange transfusion.

Three studies carried out on 2946 participants by using different thresholds for exchange transfusion. Brown 1985 reported a 
marked decrease in ET requirement (RR $0.20 ; 95 \% \mathrm{Cl} 0.13$ to $0.31)^{16}$ by using lower threshold while Tripathi 2006 and Morris 2008 used higher threshold and did not observe any major change in the rate of ET (RR 0.66; $95 \% \mathrm{Cl} 0.19$ to 2.28). 17,18

A Dhaka study reported prophylactic phototherapy in premature neonates with <1500 grams was effective and safe compared to controls. ${ }^{19} \mathrm{~A}$ Khalil OA et al study also favored that prophylactic phototherapy was capable to decrease the bilirubin values significantly in preterm infants. ${ }^{20}$ No universal standard guidelines are available while different protocols are being followed in different institutions across the country to treat neonatal jaundice. Although, some pediatricians manage preterm aggressively considering them as high-risk group and start phototherapy early to prevent significant rise in serum bilirubin which may warrant exchange transfusion.

Our rationale was to find out prophylactic phototherapy started soon after birth (within 6 hours) in preterm may inhibit the serum bilirubin from attaining a level that would necessitate exchange transfusion. So, morbidity and mortality associated with ET procedure may be avoided. Reduced frequency of exchange transfusion is also cost effective which is advantageous for developing countries like Pakistan. The study will also be beneficial because at national level very few such studies conducted so far.

\section{METHODOLOGY}

Study Design: Randomized control trial.

Settings: Neonatal Unit of Pediatrics department, Sir Ganga Ram Hospital, Lahore Pakistan.

Duration: September 2018 to June 2019.

Sample Technique: Random sampling technique.

Sample Size: Total two hundred preterm neonates.

Inclusion Criteria: 100 cases in each group born before 37 weeks from the 1st day of the last menstrual period were recruited in this study.

Exclusion Criteria: Preterm with birth asphyxia (Apgar score < 6 at 5 minutes of life), respiratory distress syndrome (tachypnea, grunting, subcostal recession with evident radiological changes), sepsis (positive blood culture i.e. $>10$ microorganisms/HPF) or its risk factors in mothers (premature rupture of membrane $>18$ hours), congenital anomalies, and presence of ABO or Rh incompatibility (Positive Coomb's Test) were excluded. Additionally, neonates with bilirubin in exchange transfusion range before the start of phototherapy were also removed from study.

Data Collection Procedure: After taking ethical approval from institutional review board, an informed written consent was also taken from parents of neonates. A semi structured proforma was designed and used for data collection. In group A, prophylactic phototherapy was commenced within first 6 hours of life after covering eyes and genitalia irrespective of their bilirubin levels up to 7 days. In group B, phototherapy was applied when the STB had touched to a pre-specified level where its therapeutic use is indicated ${ }^{21}$ and continued till their bilirubin values dropped below therapeutic range of phototherapy. Total serum bilirubin was measured daily by spectrophotometric method in both groups. Direct and indirect bilirubin was also measured. Exchange transfusion was performed when total bilirubin level exceeded the phototherapy range and reached the specified level for exchange. Efficacy was considered if bilirubin levels did not reach exchange transfusion level during application of phototherapy.

Bias was addressed by having investigations from one laboratory and effect modifiers were addressed through exclusion criteria. All data was collected by using questionnaire that include gestational age of baby, mode of delivery, gender and birth weight. Daily serum bilirubin values were recorded. Number of exchange transfusions required and duration of phototherapy was also noted in both groups.

Data was entered and analysis made with SPSS version 21. Frequency and percentages were computed for categorical variables like gender, mode of delivery and exchange transfusion for both groups. Mean and standard deviation were calculated for quantitative data include gestational age, birth weight and serum total bilirubin levels (including direct and indirect bilirubin). Chi-square and $t$ test for independent sample was used to compare the efficacy of prophylactic and therapeutic phototherapy in preterm neonates with $p$-value < 0.05 as significant.

\section{RESULTS}

The study participants included 200 neonates with jaundice. There were $54 \%$ males and $46 \%$ females in group A while $51 \%$ males and $49 \%$ females in group B. Gestational age analysis showed that $41 \%$ and $32 \%$ neonates born at $34-35.6$ weeks while $59 \%$ and $68 \%$ were between $36-36.6$ weeks in group $A$ and group $B$ respectively. Table 01 showed that mean gestation age and birth weight were comparable in both groups.

Table 1: Demographic characteristics of preterm of both groups $(n=200)$

\begin{tabular}{|c|c|c|c|c|}
\hline \multicolumn{2}{|c|}{ Variables } & $\begin{array}{c}\text { Group } A \\
n=100\end{array}$ & $\begin{array}{c}\text { Group B } \\
n=100\end{array}$ & $\begin{array}{c}\text { P- } \\
\text { Value }\end{array}$ \\
\hline \multicolumn{2}{|c|}{$\begin{array}{c}\text { Birth weight(grams) } \\
\text { mean } \pm \text { SD }\end{array}$} & $2000 \pm 400$ & $1900 \pm 500$ & 0.120 \\
\hline \multicolumn{2}{|c|}{$\begin{array}{c}\text { Gestational Age (weeks) } \\
\text { mean } \pm \text { SD }\end{array}$} & $35.4 \pm 0.9$ & $35.6 \pm 0.7$ & 0.0808 \\
\hline \multirow{2}{*}{$\begin{array}{c}\text { Number } \\
\text { according to } \\
\text { gestational } \\
\text { age }\end{array}$} & $\begin{array}{l}34-35.6 \\
\text { weeks }\end{array}$ & $41 \%$ & $32 \%$ & \multirow[b]{2}{*}{0.1862} \\
\hline & $\begin{array}{l}36-36.6 \\
\text { weeks }\end{array}$ & $59 \%$ & $68 \%$ & \\
\hline \multirow[b]{2}{*}{ Sex } & Male (\%) & $54 \%$ & $51 \%$ & \multirow[b]{2}{*}{0.6709} \\
\hline & $\begin{array}{c}\text { Female } \\
(\%)\end{array}$ & $46 \%$ & $49 \%$ & \\
\hline \multirow{2}{*}{$\begin{array}{l}\text { Mode of } \\
\text { Delivery }\end{array}$} & $\begin{array}{l}\text { Vaginal } \\
(\%)\end{array}$ & $43 \%$ & $46 \%$ & \multirow{2}{*}{0.6695} \\
\hline & $\begin{array}{l}\text { Cesarean } \\
(\%)\end{array}$ & $57 \%$ & $54 \%$ & \\
\hline
\end{tabular}

On day one, no difference was observed in mean total bilirubin levels in both groups (table 02). Mean serum bilirubin level was lower in the prophylactic group on second to sixth days in 
comparison to therapeutic group with statistically significant difference on $4^{\text {th }}$ and $5^{\text {th }}$ days $(p<0.00001)$ whereas at day 7 it was significantly lower in therapeutic group ( $p$ 0.0170). The peak mean STB level was found on $3^{\text {rd }}$ and $4^{\text {th }}$ days in groups $A$ and $B$ respectively. The duration of phototherapy in group $A$ was $147 \pm 34.25$ compared to $98 \pm 27.10$ in group B with significant $p$ value $(p<0.00001)$.

Table 2: Group A \& B: Comparison of serum total bilirubin (STB) in the first week of life

\begin{tabular}{|c|c|c|c|c|c|c|c|}
\hline \multirow[t]{2}{*}{ Age } & \multicolumn{3}{|c|}{$\begin{array}{c}\text { Group A (Prophylactic) }(n=100) \\
\text { Serum Bilirubin(mg/dl) Mean } \pm S D\end{array}$} & \multicolumn{3}{|c|}{$\begin{array}{c}\text { Group B (Therapeutic) }(n=100) \\
\text { Serum Bilirubin(mg/dl) Mean } \pm \text { SD }\end{array}$} & \multirow[t]{2}{*}{ P-value } \\
\hline & Direct & Indirect & Totala & Direct & Indirect & Total $^{b}$ & \\
\hline 1 ST DAY & $0.6 \pm 0.5$ & $4 \pm 2$ & $4.6 \pm 2.5$ & $0.6 \pm 0.1$ & $4 \pm 1.5$ & $4.6 \pm 1.6$ & $>0.999$ \\
\hline $2^{\mathrm{ND}} \mathrm{DAY}$ & $0.6 \pm 0.2$ & $6 \pm 3$ & $6.6 \pm 3.2$ & $0.4 \pm 0.2$ & $6.9 \pm 2.3$ & $7.3 \pm 2.5$ & 0.0864 \\
\hline $3^{\text {RD DAY }}$ & $0.7 \pm 0.3$ & $9 \pm 4$ & $9.7 \pm 4.3$ & $0.7 \pm 0.3$ & $10 \pm 4.5$ & $10.7 \pm 4.8$ & 0.1224 \\
\hline $4^{\text {TH }}$ DAY & $0.6 \pm 0.1$ & $8 \pm 3.5$ & $8.6 \pm 3.6$ & $0.6 \pm 0.2$ & $12 \pm 5.3$ & $12.6 \pm 5.5$ & $<0.00001$ \\
\hline $5^{\text {TH }}$ DAY & $0.4 \pm 0.2$ & $7.4 \pm 3.3$ & $7.8 \pm 3.5$ & $0.5 \pm 0.2$ & $10 \pm 4.1$ & $10.5 \pm 4.3$ & $<0.00001$ \\
\hline $6^{\text {TH }}$ DAY & $0.5 \pm 0.1$ & $6.7 \pm 1.7$ & $7.2 \pm 1.8$ & $0.3 \pm 0.1$ & $7 \pm 2.7$ & $7.3 \pm 2.8$ & 0.7642 \\
\hline $7^{\text {TH }}$ DAY & $0.4 \pm 0.1$ & $6.0 \pm 1.8$ & $6.4 \pm 1.9$ & $0.5 \pm 0.2$ & $5.2 \pm 0.2$ & $5.7 \pm 2.2$ & $<0.0170$ \\
\hline
\end{tabular}

Note: P-values are calculated on total bilirubin( $\mathrm{mg} / \mathrm{dl})$ level of prophylactic and therapeutic groups

Three infants of group A required exchange transfusion as compared to 8 patients in group B. Prophylactic phototherapy was efficacious in $97 \%$ of preterm compared to $92 \%$ in therapeutic group but no statistical significant difference with regard to efficacy was found between two groups $(p=0.1209)$. Among 3 patients of group $A$ who underwent exchange transfusion, 2 were males and 1 female as compared to group $B$ in which there were 3 males and 5 female babies. Mean birth weight was $1900 \pm 500 \mathrm{~g}$ and $2000 \pm 400 \mathrm{~g}$ in group $A$ and $B$ respectively who underwent exchange transfusion. Mean gestational age of patients in group A was 35 weeks and it was $35 \pm 1$ week in group $B$.

\section{DISCUSSION}

Unconjugated bilirubin is neurotoxic and can lead to permanent neurologic sequelae in neonates who stay alive (kernicterus). In low middle-income countries (LMICs), its prevalence is said to be high but data collection is poor and inconstant. According to the Child Health Epidemiology Reference Group (CHERG), kernicterus prevalence is reported to be $73 / 100,000$ live births in LMICs ${ }^{22}$ paralleled with $0.4-2.7$ cases per 100,000 births in Europe and North America (HIC). ${ }^{23,24}$

Mortality from physiologic jaundice per se should not take place but associated with extreme hyperbilirubinemia (STB $>25 \mathrm{mg} / \mathrm{dl}$ ) due to other causes and found to be high $(119 / 100,000$ live births) in South Asia, Eastern Europe/ Central Asia, SubSaharan Africa and Latin America in comparison with 1/100,000 births in HIC. ${ }^{22} \mathrm{So}$, the presence of neonatal jaundice may need diagnostic evaluation as STB levels can increase markedly in some infants which is worrisome and alarming.

In this study, peak bilirubin levels were found on third and fourth days of life in prophylactic and therapeutic groups respectively. This finding differ from an Iraqi study that revealed peak STB levels on fifth day after birth in both groups ${ }^{20}$. In contrast a study from Brazil, ${ }^{25}$ reported peak bilirubin level on $7^{\text {th }}$ day in babies who received early phototherapy and on $2^{\text {nd }}$ day in late group.
Researches by Tripathi $i^{17}$ and Mosayebi $Z$ et al26also did not find any dissimilarity in the time at which highest serum bilirubin level was reached in these groups.

Although prophylactic phototherapy was effective in maintaining lower bilirubin levels compared to therapeutic group but statistically significant difference between them was obvious on fourth and fifth days $(p<0.00001)$. Moreover, despite starting early therapy, these neonates needed phototherapy for longer duration (147 \pm 34.25 vs $98 \pm 27.01$ hrs) with statistically significant $p$ value ( $p$ 0.00001). This result is consistent with Iranpour $\mathrm{R}$ et al study, conducted on 60 preterm jaundiced newborns weighing 1000 - 1500 grams ${ }^{27} \mathrm{~A}$ similar finding was also reported by Mannan MA et al. ${ }^{19}$ The possible reason for longer duration in group A could be that phototherapy only can act efficiently if sufficient amount of bilirubin is present in serum, so takes more time to bring bilirubin levels lower to the safe range. In group B it was only applied when STB reached to therapeutic range for phototherapy, hence resulted in shorter duration.

Regarding exchange transfusion, Mosayebi $Z$ et al study 26 revealed high rate of exchange transfusion in prophylactic group (33\% vs $7 \%$ ) so decision about early phototherapy should be customized. Other studies did not find any difference for need of ET in both groups. ${ }^{17,18} \mathrm{It}$ contradicts with our study result. Our respondents in prophylactic group had lower need for exchange transfusion (3\% versus $8 \%$ ) although it proved to be statistically insignificant $(p=0.1209)$. A Cochrane review by Okwundu $\mathrm{Cl}$ highlighted the role of prophylactic phototherapy to lower exchange transfusion rate and risk of neurodevelopmental impairment in preterm or low birth weight infants. ${ }^{28}$

\section{CONCLUSION}

In current study, preterm neonates who applied prophylactic phototherapy had less need of exchange transfusion which itself is associated with many complications. Although, no statistical significant difference in term of ET was found between two 
groups, so physicians should take decision on individual basis but in high risk preterm infants phototherapy can be applied as a prophylactic measure in order to reduce the frequency of invasive procedure.

\section{LIMITATIONS}

This study was carried out at a single tertiary care hospital with marginally adequate sample size. So, a multi-center approach with large sample size can give more broader and clear picture.

\section{SUGGESTIONS / RECOMMENDATIONS}

Every hospital where babies are born, or which provide neonatal emergency services should practice a system that includes quick assessment and management of infants with jaundice by using standard operating procedure and triage algorithm. The aim of such a protocol is the swift recognition of associated risk and minimize the time required to consider prophylactic phototherapy which may help in reducing the frequency of exchange transfusion, hence associated mortality and morbidity can be avoided.

\section{CONFLICT OF INTEREST / DISCLOSURE}

It was a non-funded research study where author did not receive financial incentive from institution or elsewhere.

\section{ACKNOWLEDGEMENTS}

We are grateful to our trainee doctors who assisted us in the collection of patient information. We would also like to thank Prof. Dr. Rashid Mehmood for his support and requisite facilitation during study period.

\section{REFERENCES}

1. Micheal R, Baun D, Jones MF, Vichinsky $E$. Jaundice and Hyperbilirubinemia in the Newborn In: Kliegman RM, St. Geme JW, Blum NJ, Shah SS, Tasker RC, Wilson KM, editors. Nelson text book of pediatrics. 21sted. New York: Elsevier Saunders, 2020:871-80.

2. Slusher TM, Zamora TG, Appiah D, Stanke JU, Strand MA, Lee BW, et al. Burden of severe neonatal jaundice: a systematic review and meta-analysis. BMJ Paediatr Open. 2017;1(1):e000105.

3. Olusanya BO, Kaplan M, Hansen TWR. Neonatal hyperbilirubinaemia: a global perspective. Lancet Child Adolesc Health. 2018;2(8):610-620.

4. Bhutani VK, Zipursky A, Blencowe H, Khanna R, Sgro M, et al. Neonatal hyperbilirubinemia and Rhesus disease of the newborn: incidence and impairment estimate for 2010 at regional and global levels. Pediatr Res. 2013;74(Suppl 1):86-100.

5. Greco C, Arnolda G, Boo NY, et al. Neonatal Jaundice in Lowand Middle-Income Countries: Lessons and Future Directions from the 2015 Don Ostrow Trieste Yellow Retreat. Neonatology. 2016;110 (3):172-180.

6. Korejo HB, Bhurgri GR, Bhand S, Qureshi MA, Dahri GM, Chohan RK. Risk factors for kernicterus in neonatal jaundice. Gomal J Med Sci. 2010;8(1):12-5.

7. Almeida MF. When should we start phototherapy in preterm newborn infants?. Journal de Pediatria. 2004;80(4):285-90.
8. Newman TB, Maisels MJ. Evaluation and treatment of Jaundice in the term newborn: A kinder, gentle approach. Pediatrics 1992:89:819-831.

9. Jackson JC, Adverse events associated with exchange transfusion in healthy and ill newborns Pediatrics 1997; 99:7-8.

10. Hansen TW. Treatment of neonatal jaundice. Tidsskr Nor Laegeforen. 2005;125(5):594-8.

11. Mabogunje CA, Olaifa SM, Olusanya BO. Facility-based constraints to exchange transfusions for neonatal hyperbilirubinemia in resource-limited settings. World J Clin Pediatr. 2016;5(2):182-90.

12. Adebami $\mathrm{O}$. Factors associated with the incidence of acute bilirubin encephalopathy in Nigerian population. J Pediatric Neurology. 2011;9:347-53.

13. Eneh AU, Oruamabo RS. Neonatal jaundice in a special care baby unit (SCBU) in port harcourt, nigeria: a prospective study. AJOL. 2008;2(2):110-7.

14. National Neonatal Perinatal Database. Morbidity and mortality among outborn neonates at 10 tertiary care institutions in India during the year 2000. J Trop Pediatr 2004;50:170-4.

15. Salas AA, Mazzi E. Exchange transfusion in infants with extreme hyperbilirubinemia: an experience from a developing country. Acta Paediatr. 2008;97:754-8.

16. Brown AK, Kim MH, Wu PYK, Bryla DA. Efficacy of phototherapy in prevention and management of neonatal hyperbilirubinemia. Pediatrics. 1985;75:393-441.

17. Tripathi S, Saili A. Effect of prophylactic phototherapy on neonatal hyperbilirubinemia of prematures. Indian J Medical Sci. 2006;60(9):385-7.

18. Morris BH, Oh W, Tyson JE, Stevenson DK, Phelps DL, O'Shea TM, et al; NICHD Neonatal Research Network. Aggressive vs. conservative phototherapy for infants with extremely low birth weight. N Engl J Med. 2008;359(18):1885-96.

19. Mannan MA, Jahan I, Moni SC, Hasan Z, Dey AC, Shahidullah M. Efficacy of prophylactic phototherapy for prevention of hyperbilirubinemia in very low birth weight newborns. BSMMUL. 2016; 6(2):151-5.

20. Khalil OA, Rafeeq HM, Noaman NG. Role of Prophylactic Phototherapy in the Management of very Low Birth weight Newborns with Hyperbilirubinemia in Comparison to Therapeutic Phototherapy with their Gender. Diyala J Medi. 2019;16(2):64-71.

21. Thor WR Hansen. http://emedicine.medscape.com/article/974786-overview. Pediatrics 2004; 114(1):297.

22. Bhutani VK, Zipursky A, Blencowe H, Khanna R, Sgro M, Ebbesen $F$, et al: Neonatal hyperbilirubinemia and Rhesus disease of the newborn: incidence and impairment estimate for 2010 at regional and global levels. Pediatr Res. 2013;74(suppl 1):86-100.

23. Maisels MJ, Newman TB. Prevention, screening and postnatal management of neonatal hyperbilirubinemia. Stevenson DK, Maisels MJ, Watchko JF. Care of the jaundiced neonate. New York: McGraw-Hill; 2012. 175-94.

24. Bhutani VK, Johnson L: Kernicterus in the 21st century: frequently asked questions. J Perinatol 2009;29(1):20-4.

25. Leite MGC, Facchini FP. Evaluation of two guidelines for the management of hyperbilirubinemia in newborn babies weighing less than 2,000 g. J de Pediatria. 2004;80(4):285-90.

26. Moysayebi Z, Homayounfar M, Nariman S, Sagheb S, Movahedian AH. Prophylactic Versus Therapeutic Phototherapy in Very Low Birth Weight Infants. J Compr Ped. 2015;6(4):e31216. 
27. Iranpour $R$, Mohammadizadeh, $M$, Nazem-Sadati SS. Comparison of Two Phototherapy Methods (Prophylactic vs Therapeutic) for Management of Hyperbilirubinemia in Very Low Birth Weight Newborns. Iran J Pediatr. 2011;21(4):425-30.

28. Okwundu $\mathrm{Cl}$, Okoromah CAN, Shah PS. Prophylactic phototherapy for preventing jaundice in preterm or low birth weight infants. Cochrane Database of Systematic Reviews. Evid. -Based Child Health. 2013;8(1):204-49.

\section{AUTHORSHIP CONTRIBUTION}

\begin{tabular}{|c|c|}
\hline $\begin{array}{l}\text { Dr. Fouzia Ishaq } \\
\text { Associate Professor, Pediatrics } \\
\text { Fatima Jinnah Medical University / Sir } \\
\text { Ganga Ram Hospital, Lahore Pakistan }\end{array}$ & $\begin{array}{l}\text { Conceive Idea, Study Design, } \\
\text { Review of Literature, Drafting }\end{array}$ \\
\hline $\begin{array}{l}\text { Dr. Sidra Sehrish } \\
\text { Senior Registrar, Pediatrics } \\
\text { Allied Hospital, Faisalabad Pakistan }\end{array}$ & $\begin{array}{l}\text { Data Collection, Methodology, } \\
\text { Data Compilation, Drafting }\end{array}$ \\
\hline $\begin{array}{l}\text { Dr. Asma Anwar } \\
\text { Assistant Professor, Pediatrics } \\
\text { Fatima Jinnah Medical University / Sir } \\
\text { Ganga Ram Hospital, Lahore Pakistan }\end{array}$ & $\begin{array}{l}\text { Literature Review, Discussion, } \\
\text { Data Collection }\end{array}$ \\
\hline $\begin{array}{l}\text { Dr. Rameeza Kaleem } \\
\text { Assistant Professor, Pediatrics } \\
\text { Fatima Jinnah Medical University / Sir } \\
\text { Ganga Ram Hospital, Lahore Pakistan }\end{array}$ & $\begin{array}{l}\text { Discussion, Referencing, } \\
\text { Literature Review, Drafting the } \\
\text { Manuscript }\end{array}$ \\
\hline $\begin{array}{l}\text { Dr. Summaira Naveed } \\
\text { Associate Professor, Pediatrics } \\
\text { Services Institute of Medical Sciences, } \\
\text { Lahore Pakistan }\end{array}$ & $\begin{array}{l}\text { Proof Reading, Literature } \\
\text { Review }\end{array}$ \\
\hline $\begin{array}{l}\text { Tayyba Rahat } \\
\text { Statistical Officer, } \\
\text { Pakistan Research Health Council, } \\
\text { Lahore Pakistan }\end{array}$ & $\begin{array}{l}\text { Data Analysis, Interpretation of } \\
\text { Results }\end{array}$ \\
\hline
\end{tabular}

